\title{
Article \\ Parametric Random Vibration Analysis of an Axially Moving Laminated Shape Memory Alloy Beam Based on Monte Carlo Simulation
}

\author{
Ying Hao ${ }^{1}$, Ming Gao ${ }^{2, *(1)}$ and Jiajie Gong ${ }^{1}$ \\ 1 College of Civil Engineering \& Mechanics, Hebei Provincial Key Laboratory of Mechanical Reliability for \\ Heavy Equipments and Large Structures, Yanshan University, Qinhuangdao 066004, China; \\ hy0505@ysu.edu.cn (Y.H.); gongjiss@shu.edu.cn (J.G.) \\ 2 Mechanical and Electronic Engineering College, Shandong Agricultural Equipment Intelligent Engineering \\ Laboratory, Shandong Provincial Key Laboratory of Horticultural Machineries and Equipments, \\ Shandong Agricultural University, Tai'an 271018, China \\ * Correspondence: gaom@sdau.edu.cn
}

Citation: Hao, Y.; Gao, M.; Gong, J. Parametric Random Vibration Analysis of an Axially Moving Laminated Shape Memory Alloy Beam Based on Monte Carlo Simulation. Materials 2022, 15, 562. https://doi.org/10.3390/ma15020562 Academic Editors: Mauro Zarrelli and Andrea Sellitto

Received: 12 October 2021 Accepted: 10 January 2022 Published: 12 January 2022

Publisher's Note: MDPI stays neutral with regard to jurisdictional claims in published maps and institutional affiliations.

Copyright: (C) 2022 by the authors. Licensee MDPI, Basel, Switzerland. This article is an open access article distributed under the terms and conditions of the Creative Commons Attribution (CC BY) license (https:/ / creativecommons.org/licenses/by/ $4.0 /)$.

\begin{abstract}
The study of the bifurcation, random vibration, chaotic dynamics, and control of laminated composite beams are research hotspots. In this paper, the parametric random vibration of an axially moving laminated shape memory alloy (SMA) beam was investigated. In light of the Timoshenko beam theory and taking into consideration axial motion effects and axial forces, a random dynamic equation of laminated SMA beams was deduced. The Falk's polynomial constitutive model of SMA was used to simulate the nonlinear random dynamic behavior of the laminated beam. Additionally, the numerical of the probability density function and power spectral density curves was obtained through the Monte Carlo simulation. The results indicated that the large amplitude vibration character of the beam can be caused by random perturbation on axial velocity.
\end{abstract}

Keywords: axial motion with variable velocity; laminated SMA beam; random parametric excitation; Monte Carlo simulation

\section{Introduction}

Axially moving structures are widely found in aerospace, civil engineering, machinery, and transportation industries. In theoretical analysis, these structures are modeled as beams, chords, or plates. So far, the nonlinear vibration behaviors of axially moving beams, chords, and plates have been extensively studied. Chen et al. [1] applied a multiple-dimension Lindsted-Poincare (L-P) process to examine internal resonance in the vibration of axially moving beams. Ding et al. [2] used a multi-scale procedure to analyze the stability and steady-state response of axially moving viscoelastic beams. Yang et al. [3] established a dynamics model of an axially moving viscoelastic beam and discussed how axial motion parameters and system viscoelastic coefficients affect the bifurcation behavior of this beam. Liu et al. [4] compared the vibration characteristics of three typical types of axially moving structures-Euler beams, panels, and plates with two opposite sides simply supported and the other two left free. Tang et al. [5] probed into the transverse nonlinear vibration of a viscoelastic plate moving axially with variable velocity. Al-Bedoor et al. [6] found the approximate analytical solution of beam vibration during axial motion. Chen et al. [7] investigated the nonlinear vibration of axially moving beams using the harmonic balance method. Burak et al. [8] used a method of multiple time scales (a perturbation method) to examine the nonlinear vibration and stability of axially moving beams with variable velocity and axial force values. Lenci et al. [9] investigated the nonlinear free oscillations of a planar Timoshenko straight beam using the asymptotic expansion method. Xiao et al. [10], Liu et al. [11], and Jin et al. [12] studied vibration complex problems in other important engineering structures. 
Shape memory alloys (SMAs) feature particular shape memory and pseudo elasticity characteristics. They are more sensitive to stress and temperature and are more deformable and elastic than common metals [13]. Laminated beams are a usual form of laminated structures, which are structures composed of SMAs on the surface and linear elastic material in between. Ren et al. [14-16] carried out a succession of studies on SMA fiber hybrid laminated beams. They developed a theoretical analysis model describing the natural frequency of a kind of hybrid laminated beam composed of SMA fibers laminated with common fibers and observed the effects of the content, installation angel, and transverse shear deformation of SMA fibers. Collet et al. [17] considered a hypothesis that SMA remains symmetric under tensile, compressive, and temperature loading and tested the dynamical behaviors of an SMA beam by applying external moving loads on the material. Through hierarchical Rayleigh-Ritz simulation, de Matos Junior et al. [18] studied the nonlinearity of the aeroelastic behavior of stiffened SMA hybrid composite (SMAHC) cylindrical plates on a carbon fiber-SMAHC laminated plate. Zhang et al. presented an experimental study on the random vibration of aviation conduits with SMA joints [19]. Razavilar et al. [20] developed a semi-analytical procedure for studying the free vibration and forced vibration of an SMA beam with pseudoelastic behavior. They established the control dynamics equations of a deformation-strain-coupled SMA beam and analyzed its thermodynamic properties with phase trajectory. Nassiri-monfared et al. [21] characterized the thermomechanical behavior of a beam reinforced with SMA elements on an improved Brinson polynomial constitutive model. Zhang [22] tested how external excitation and structural parameters (parameters related to the thickness ratio between the SMA layer and the beam substrate) affect the one-third subharmonic and third superharmonic resonance of an SMA-laminated beam supported at both ends. Nejati et al. [23] analyzed the thermal vibration of SMA hybrid composite double-curved sandwich panels. Samadpour et al. [24] looked into the nonlinear aero-thermal flutter postponement of supersonic-laminated composite beams with SMA.

Given the possibility of complex nonlinear dynamics in the system, such as sharp vibration, the resonance of parametric vibration with forced vibration, bifurcation, and chaos, in response to axial velocity and external excitation, studying the transverse vibration mechanism of axially moving beams is both theoretically and practically useful for optimizing engineering system components. By considering the effects of shear modulus and moment of inertia, Li et al. [25] used the multiple time scale method to examine the steady-state response of an axially moving viscoelastic Timoshenko beam to forced transverse nonlinear vibration. Ding et al. [26] introduced finite support stiffness and investigated the chaotic nonlinear dynamics of an axially moving viscoelastic beam subject to a combination of external excitation and parametric excitation. Ding et al. [27] applied Timoshenko beam theory to the nonlinear dynamics studies of a structure moving axially with high speed for the first time. They derived the static balance equation of the beam, deduced the critical velocity of an axially moving Timoshenko beam and discussed the effects of system parameters on equilibrium bifurcation and critical speed. Wang et al. [28,29] discussed the magneto-elastic primary and internal resonances of axially moving conductive beams in a magnetic field. Tang et al. [30] established the nonlinear dynamics model of an axially accelerating viscoelastic beam by considering the non-uniform boundary conditions induced by the Kelvin viscoelastic constitutive relation. Through a numerical example, they analyzed the effects of material viscoelastic coefficient and axial velocity fluctuation amplitude on steady-state vibration response. Based on the Galerkin method and fourth-order Runge-Kutta method, Shao et al. [31] studied the nonlinear vibration of a thin film moving axially with variable velocity and analyzed its chaotic and bifurcation behaviors in response to changed average velocity and velocity fluctuation amplitude. Sahoo et al. [32] examined the steady-state response of an axially accelerating viscoelastic beam to dual-frequency parametric excitation both analytically and numerically. Through phase diagram, time history, and Poincare mapping analyses, they discovered the Hopf bifurcation, saddle node bifurcation, and pitch-fork bifurcation present in the system. Yang et al. [33] analyzed the stability of a 
compressible laminated beam moving with variable velocity. In addition, on the problem of random vibration, $\mathrm{Hu}$ [34-36] analyzed the response and control for random time-delay systems under wide-band random excitations and Harmonic and Wide-Band Noises.

At present, the research on the axially moving continuum mainly focuses on homogeneous materials, and the laminated structure is rarely considered in the modeling process and analysis of axially moving beams. Most of the existing literature considers nonlinear dynamic problems such as the internal resonance, principal resonance, and bifurcation of laminated beams, but there is a lack of research that considers the random disturbance of axial velocity on the nonlinear stochastic dynamic behaviors. In this dissertation, based on the force balance conditions, deformation compatibility equation, and Falk's polynomial constitutive model of SMA, the random vibration differential equation of laminated SMA beams is derived and numerically solved. The effects of random perturbation intensity and axial velocity on steady-state response are analyzed.

\section{Random Vibration Equation of Laminated SMA Beams Moving Axially with Variable Velocity}

\subsection{Polynomial Constitutive Relation of SMA}

For an SMA-laminated beam with a complex structure and complicated stress conditions, it is sometimes difficult to obtain the dynamic equation of the system by using other constitutive models, and the nonlinear dynamics characteristics of the system can be easily obtained and analyzed by using this constitutive model. Paiva and Savi's [34] research shows that the polynomial model can qualitatively describe the dynamic behavior of SMA. This dissertation used this quantic polynomial stress-strain constitutive relation of SMA in Ref. [37], which was written as

$$
\sigma=a\left(T-T_{M}\right) \varepsilon-b \varepsilon^{3}+e \varepsilon^{5}
$$

where $a, b$ and $e=\frac{b^{2}}{4 a\left(T_{\mathrm{A}}-T_{\mathrm{M}}\right)}$ are material constants; $T_{\mathrm{A}}$ is the temperature above which austenite is stable, and $T_{\mathrm{M}}$ is the temperature below which marten site is stable; $a=1 \times 10^{3} \mathrm{MPa} / \mathrm{K}$, $b=40 \times 10^{6} \mathrm{MPa} / \mathrm{K}, T_{\mathrm{A}}=313 \mathrm{~K}$, and $T_{\mathrm{A}}=287 \mathrm{~K}$, which were obtained from experiments in Ref. [37], and the stress-strain curve is shown in Figure 4-2 (Ref. [37]).

\subsection{Dynamics Equation of Laminated SMA Beams}

The geometric model of a laminated beam with length $L$, width $b_{1}$, substrate beam height $H$, and SMA height $h$ for both the upper and lower layers is established, as shown in Figure 1. $\xi(t)$ is the random perturbation term on axial velocity, which can be nominally seen as Gaussian white noise with noise intensity D. $P_{z}(x, t)$ and $P$ are the uniform loading and axial pressure acting on the laminated beam.

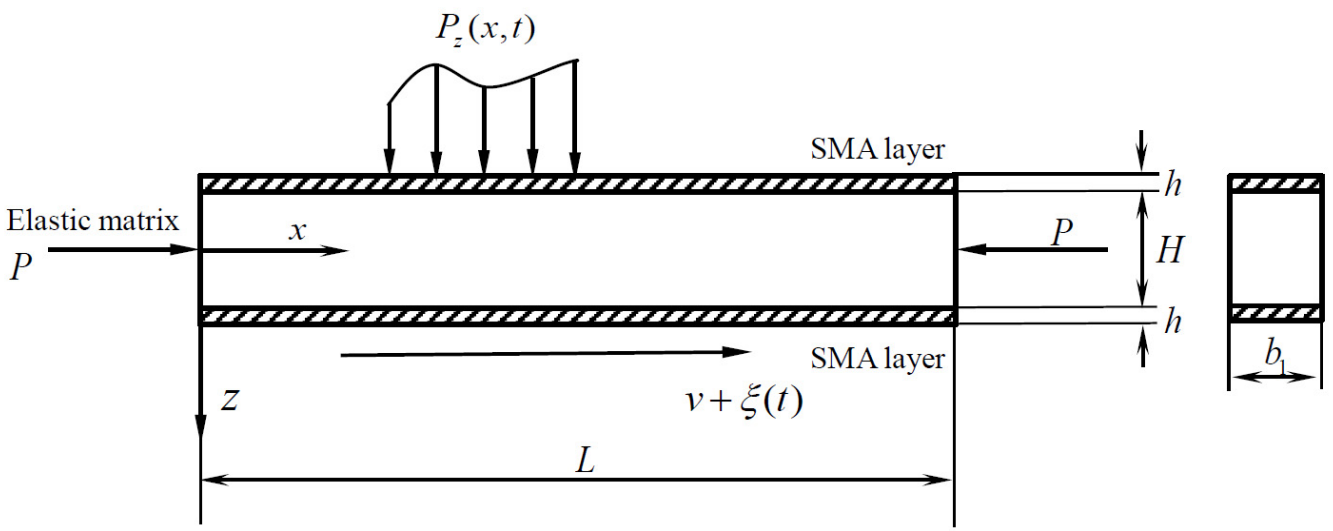

Figure 1. The structural diagram of the axially moving laminated SMA beam. 
In the figure, $o x z$ is the stationary coordinate system; the axial velocity is $V=v+\xi(t)$, with traverse displacement being recorded as $\omega(x, t)$; the beam transverse velocity is $\frac{\mathrm{d} w}{\mathrm{~d} t}=\frac{\partial w}{\partial t}+V \frac{\partial w}{\partial x}$, and the acceleration is $\frac{\mathrm{d}^{2} w}{\mathrm{~d} t^{2}}=\frac{\partial^{2} w}{\partial t^{2}}+2 V \frac{\partial^{2} w}{\partial x \partial t}+V^{2} \frac{\partial^{2} w}{\partial x^{2}}$. Assuming the forced excitation, $P_{z}(x, t)=f_{0} \sin (\gamma t)$ where $f_{0}$ is the excitation amplitude. Additionally, the density of the matrix beam is $\rho$, the damping coefficient per unit length is $c$, and the elastic modulus is $E$.

Hao et al. [38,39] gives the force diagram of the micro-body (Figure 2 in Ref. [38]). Introducing the random perturbation of the axial velocity, the random transverse vibration equation of the main beam can be obtained:

$$
\begin{aligned}
& -E \frac{b_{1} H^{3}}{12} \frac{\partial^{4} w}{\partial x^{4}}+\frac{H}{2} E b_{1} H\left[\left(\frac{\partial^{2} w}{\partial x^{2}}\right)^{2}+\frac{\partial w}{\partial x} \frac{\partial^{3} w}{\partial x^{3}}\right]-b_{1} H h\left[a\left(T-T_{M}\right) \frac{H+h}{2} \frac{\partial^{4} w}{\partial x^{4}}-\frac{3}{8} b(H+h)^{3}\left(\frac{\partial w}{\partial x}\right)^{2} \frac{\partial^{4} w}{\partial x^{4}}\right. \\
& \left.-\frac{3}{4} b(H+h)^{3} \frac{\partial^{2} w}{\partial x^{2}}\left(\frac{\partial^{3} w}{\partial x^{3}}\right)^{2}+\frac{5}{32} e(H+h)^{5}\left(\frac{\partial^{2} w}{\partial x^{2}}\right)^{4} \frac{\partial^{4} w}{\partial x^{4}}+\frac{5}{8} e(H+h)^{5}\left(\frac{\partial^{2} w}{\partial x^{2}}\right)^{3}\left(\frac{\partial^{3} w}{\partial x^{3}}\right)^{2}\right] \\
& -P \frac{\partial^{2} w}{\partial x^{2}}-\rho b_{1} H \frac{d^{2} w}{d^{2}}-c \frac{\partial w}{\partial t}+P_{z}=0
\end{aligned}
$$

Considering the first-order mode, the boundary condition of simple support at both ends, the displacement solution can be set as:

$$
w(x, t)=f(t) \sin \left(\frac{\pi}{L} x\right)
$$

If the displacement solution in Equation (3) is introduced to Equation (2), we can obtain:

$$
\begin{aligned}
& \frac{b_{1} H h}{2}\left[a\left(T-T_{M}\right)(H+h)\left(\frac{\pi}{L}\right)^{4} f(t) \sin \left(\frac{\pi}{L} x\right)+\frac{3}{2} b(H+h)^{3}\left(\frac{\pi}{L}\right)^{8} f(t)^{3} \sin \left(\frac{\pi}{L} x\right) \cos ^{2}\left(\frac{\pi}{L} x\right)\right]+ \\
& \frac{b_{1} H h}{2}\left[-\frac{3}{4} b(H+h)^{3}\left(\frac{\pi}{L}\right)^{8} f(t)^{3} \sin ^{3}\left(\frac{\pi}{L} x\right)-\frac{5}{4} e(H+h)^{5}\left(\frac{\pi}{L}\right)^{12} f(t)^{5} \sin ^{3}\left(\frac{\pi}{L} x\right) \cos ^{2}\left(\frac{\pi}{L} x\right)\right]+ \\
& \frac{5 b_{1} H h}{32} e(H+h)^{5}\left(\frac{\pi}{L}\right)^{12} f(t)^{5} \sin ^{5}\left(\frac{\pi}{L} x\right)-\frac{b_{1} H^{3} E}{12}\left(\frac{\pi}{L}\right)^{4} f(t) \sin \left(\frac{\pi}{L} x\right)+P\left(\frac{\pi}{L}\right)^{2} f(t) \sin \left(\frac{\pi}{L} x\right) \\
& -\rho b_{1} H f(t) \sin \left(\frac{\pi}{L} x\right)+\rho b_{1} H v^{2}\left(\frac{\pi}{L}\right)^{2} f(t) \sin \left(\frac{\pi}{L} x\right)-2 \rho b_{1} H v f(t) \cos \left(\frac{\pi}{L} x\right)-c f(t) \sin \left(\frac{\pi}{L} x\right) \\
& +f_{0} \sin (\gamma t)=0
\end{aligned}
$$

Then, introducing the dimensionless parameters $q=f / L, \tau=t \omega_{n}, \omega_{n}=\frac{\sqrt{3}}{6} \sqrt{\frac{E H^{2} \pi^{4}}{\rho L^{4}}}$, $H_{1}=h / H, H_{2}=H / L, E_{1}=a\left(T-T_{M}\right) / E, E_{2}=b / E, E_{3}=e / E$. The continuous simply supported beam is discretized by the Galerkin method.

$$
\begin{aligned}
& \int_{0}^{1}\left[-\rho b_{1} H L \omega_{n}{ }^{2} \ddot{q} \sin \left(\frac{\pi}{L} x\right)-2 \rho b_{1} H v \omega_{n} \dot{q} \cos \left(\frac{\pi}{L} x\right)-c L \dot{q} \omega_{n} \sin \left(\frac{\pi}{L} x\right)-\frac{1}{12} b_{1} E H_{2}{ }^{3} \pi^{4} q \sin \left(\frac{\pi}{L} x\right)\right. \\
& +E_{3} \pi^{2}\left(1+H_{1}\right)^{5} q^{5} \sin ^{3}\left(\frac{\pi}{L} x\right) \cos ^{2}\left(\frac{\pi}{L} x\right)+\frac{5}{32} b_{1} H_{2}{ }^{7} H_{1} E E_{3} \pi^{12}\left(1+H_{1}\right)^{5} q^{5} \sin ^{5}\left(\frac{\pi}{L} x\right)+ \\
& E_{2} \pi^{8}\left(1+H_{1}\right)^{3} q^{3} \sin \left(\frac{\pi}{L} x\right) \cos ^{2}\left(\frac{\pi}{L} x\right)-\frac{5}{8} b_{1} H_{2}{ }^{7} H_{1} E E_{3} \pi^{12}\left(1+H_{1}\right)^{5} q^{5} \sin ^{3}\left(\frac{\pi}{L} x\right) \cos ^{2}\left(\frac{\pi}{L} x\right) \\
& -\frac{3}{8} b_{1} H_{2}{ }^{5} H_{1} E E_{2} \pi^{8}\left(1+H_{1}\right)^{3} q^{3} \sin ^{3}\left(\frac{\pi}{L} x\right)+\frac{5}{32} b_{1} H_{2}{ }^{7} H_{1} E E_{3} \pi^{12}\left(1+H_{1}\right)^{5} q^{5} \sin ^{5}\left(\frac{\pi}{L} x\right) \\
& \left.+f_{0} \sin (\gamma t) \sin \left(\frac{\pi}{L} x\right)\right]=0
\end{aligned}
$$

where:

$$
\begin{array}{ll}
\int_{0}^{\mathrm{L}} \sin ^{2}\left(\frac{\pi}{L} x\right) \mathrm{d} x=\frac{L}{2} & \int_{0}^{\mathrm{L}} \sin \left(\frac{\pi}{L} x\right) \cos \left(\frac{\pi}{L} x\right) \mathrm{d} x=0 \\
\int_{0}^{\mathrm{L}} \sin ^{4}\left(\frac{\pi}{L} x\right) \mathrm{d} x=\frac{3 L}{8} & \int_{0}^{\mathrm{L}} \sin ^{2}\left(\frac{\pi}{L} x\right) \cos ^{2}\left(\frac{\pi}{L} x\right) \mathrm{d} x=\frac{L}{8} \\
\int_{0}^{\mathrm{L}} \sin ^{6}\left(\frac{\pi}{L} x\right) \mathrm{d} x=\frac{5 L}{16} & \int_{0}^{\mathrm{L}} \sin ^{4}\left(\frac{\pi}{L} x\right) \cos ^{2}\left(\frac{\pi}{L} x\right) \mathrm{d} x=\frac{L}{16}
\end{array}
$$

Next, rearranging the differential equation, the dimensional vibration differential equation is yielded:

$$
\ddot{q}+q+c_{0} \dot{q}+k_{1} q+k_{3} q^{3}+k_{5} q^{5}+F_{0} f_{0} \sin (\gamma t)=0
$$

where: 


$$
\begin{aligned}
& c_{0}=\sqrt{\frac{12}{E H_{2}{ }^{4} \rho b_{1}{ }^{2} \pi^{4}}} c, k_{1}=-6 E_{1} H_{1}\left(1+H_{1}\right)-\frac{12 P}{6 H_{2}{ }^{3} L \pi^{2} E}-\frac{12 \rho V^{2}}{H_{2}{ }^{2} \pi^{2} E}, k_{3}=\frac{9}{8} E_{2} H_{2}{ }^{2} \pi^{4} H_{1}\left(1+H_{1}\right)^{3} \\
& k_{5}=-\frac{15}{64} E_{3} H_{2}{ }^{4} \pi^{8} H_{1}\left(1+H_{1}\right)^{5}, F_{0}=-\frac{48}{\pi^{5} b_{1} H_{2}{ }^{3} E}
\end{aligned}
$$

\section{Numerical Example and Parametric Effects}

For the axially moving laminated SMA beam, give $L=0.5 \mathrm{~m}, \mathrm{~b}_{1}=0.05 \mathrm{~m}, H=0.02 \mathrm{~m}$, $E=206 \mathrm{GPa}, \rho=7900 \mathrm{~kg} / \mathrm{m}^{3}$, and $T=300 \mathrm{~K}$. The parametric effects on system steady-state response are analyzed.

\subsection{Effect of Random Intensity}

Figure 2 compares the time histories of the system steady-state response to different random intensities (D), given $v=10 \mathrm{~m} / \mathrm{s}, \gamma=0.97$. At $\mathrm{D}=0$, the system steady-state response consists of a periodic motion, as shown in Figure 2a. As random perturbation intensity increases, transverse vibration amplitude changes randomly near 0.01, and the periodic motion disappears. A similar conclusion was found in Ref. [38] (Figure 7); as the random perturbation intensity increases, the phase diagram changes into a diffused limit cycle. It means that the steady-state response becomes more random and large amplitude vibration appears. Comparison of the four groups of time histories reveals that, with the appearance of random perturbation, a relatively large vibration amplitude appears in the system; meanwhile, the time history curve becomes less orderly.

Equation (4) is solved, and the system steady-state probability density function is simulated using the Monte Carlo algorithm, which is a method that uses random numbers to solve many computational problems based on probability and statistical theory methods. During the calculation, $10^{5}$ sample numbers are given by adopting Rung-Kutta fourthorder algorithm, the Monte Carlo simulation is run until the steady state, in the statistical sense, is reached. Figure 3 considers the effects of different random perturbation intensities on the marginal density corresponding to the system steady-state probability density function. It can be seen that increasing random perturbation intensity does not change the peak numbers in the probability density function (PDF) curves, but the value of the peaks gradually flattens and approach the origin. That is, noise intensity will not induce a phase transfer in the system.

\subsection{Effect of Axial Velocity}

Given parameters: $\gamma=0.96, D=10$. Figure 4 compares the time histories and phase diagrams of the system steady-state response to different axial velocities. As axial velocity increases, the system steady-state response gradually increases from small-amplitude oscillation; however, as axial velocity further increases to a given limit, the steady-state response amplitude gradually decreases.

From Figure 5, the value of $q$ at the marginal probability density peak first increases then decreases with increasing axial velocity. When the axial velocity is less than $90 \mathrm{~m} / \mathrm{s}$, with the increase in axial velocity, the peaks' values in the PDF curves gradually move far away from the origin. The results of the Monte Carlo simulation further show that when the axial velocity is low, the lower the velocity, the smaller the steady-state response amplitude. When the axial velocity is greater than $90 \mathrm{~m} / \mathrm{s}$, with the increase in axial velocity, the peaks' values in the PDF curves become close to the origin. 


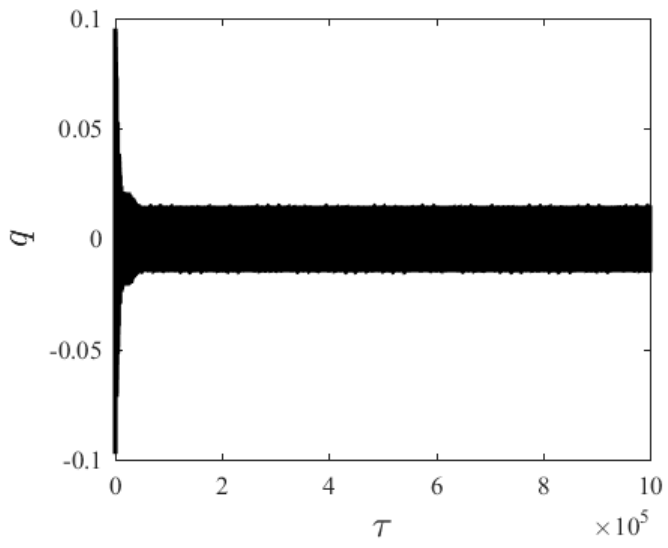

(a)

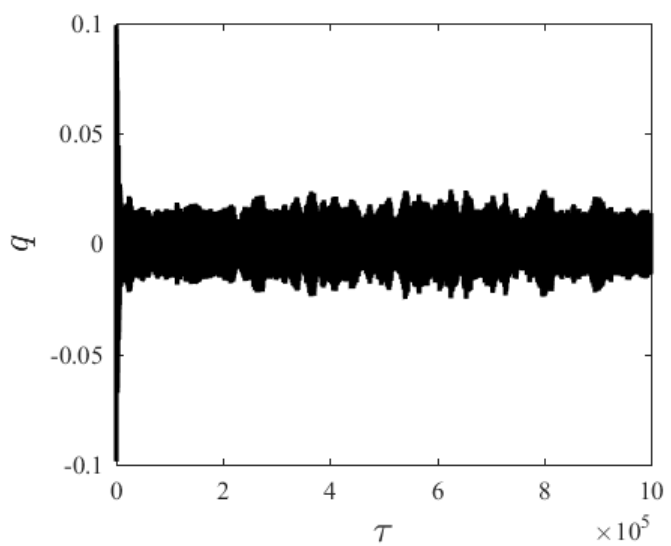

(c)

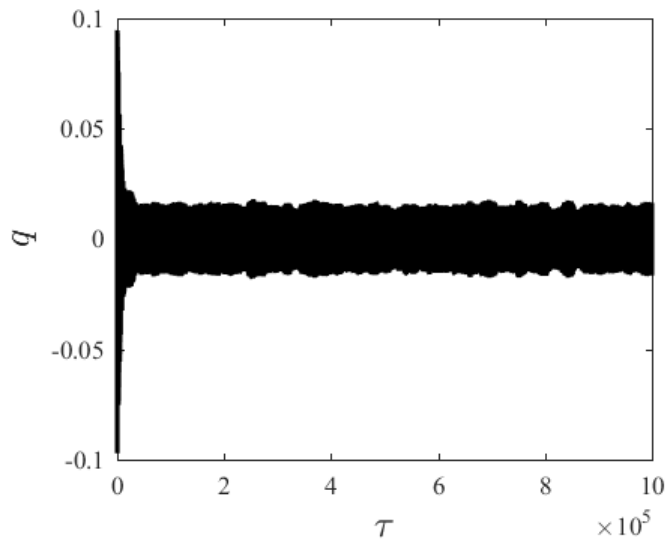

(b)

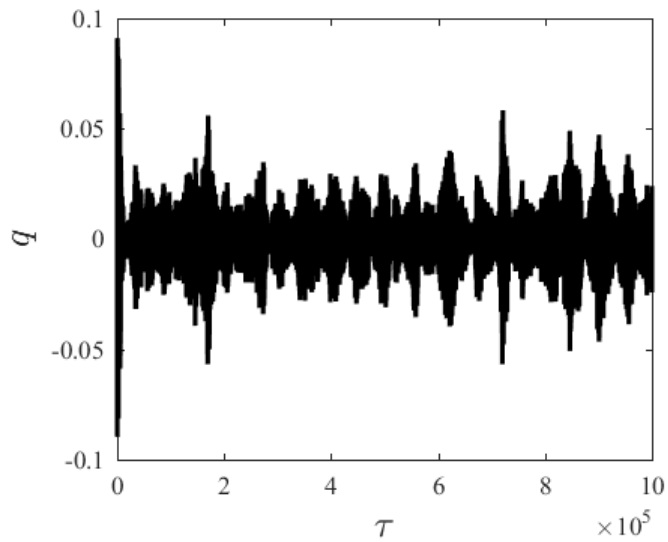

(d)

Figure 2. Time histories of $q$ under different random intensities. (a) D1 = 0, (b) D1 = 10, (c) D1 = 100, (d) $\mathrm{D} 1=500$.

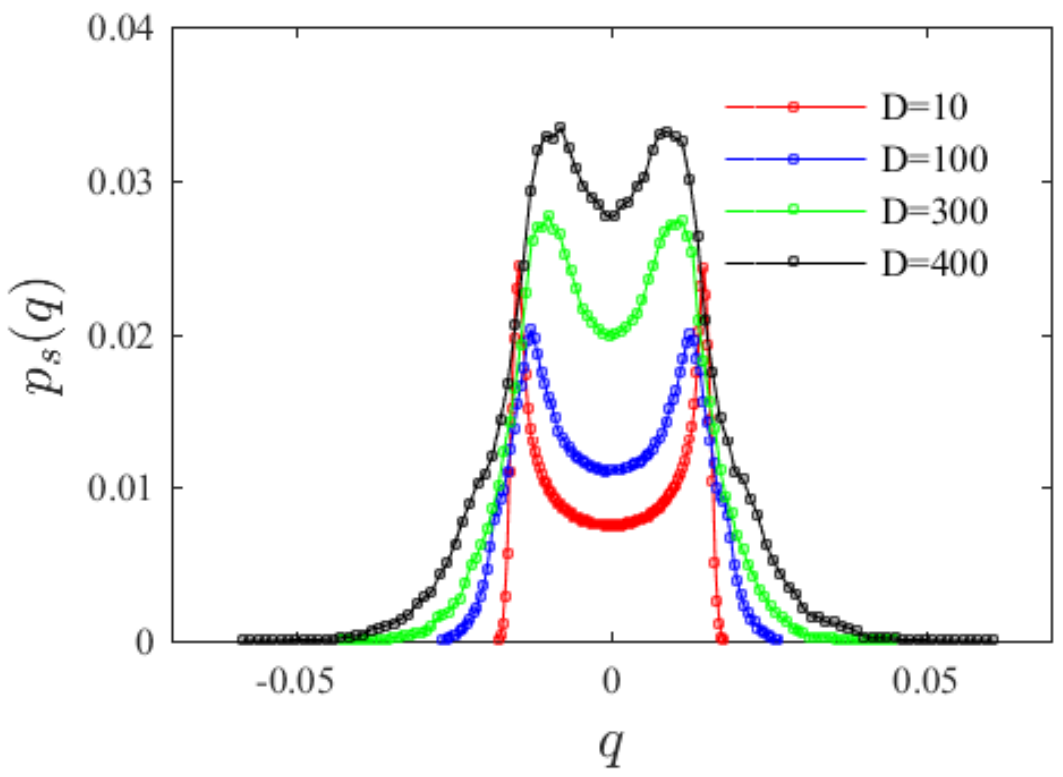

Figure 3. Variation of system marginal probability density function with random perturbation intensity. 


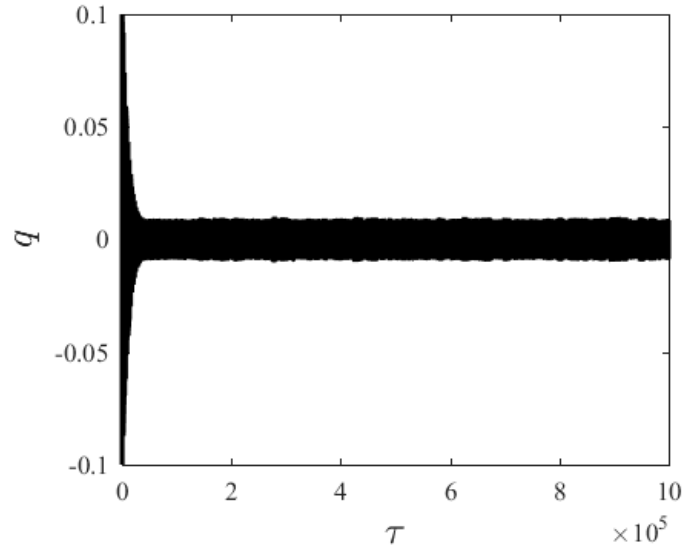

(a)

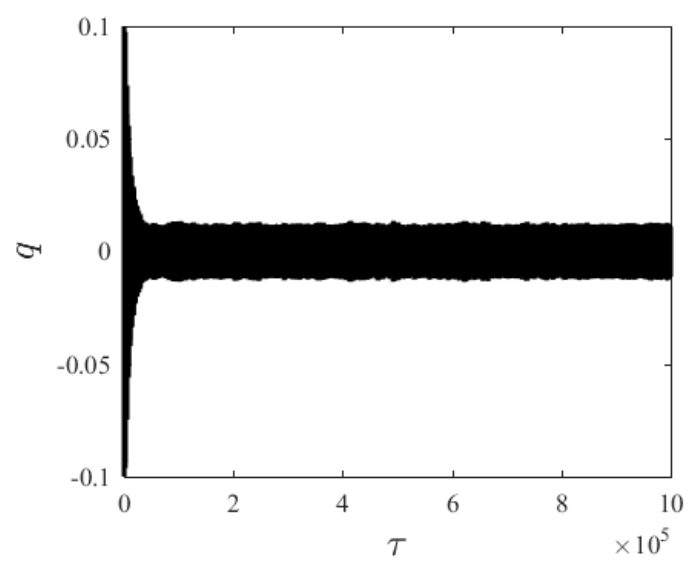

(c)

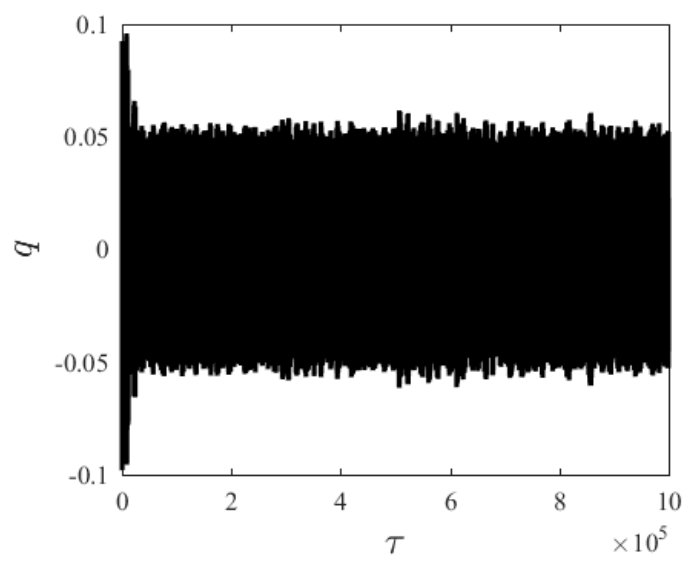

(e)

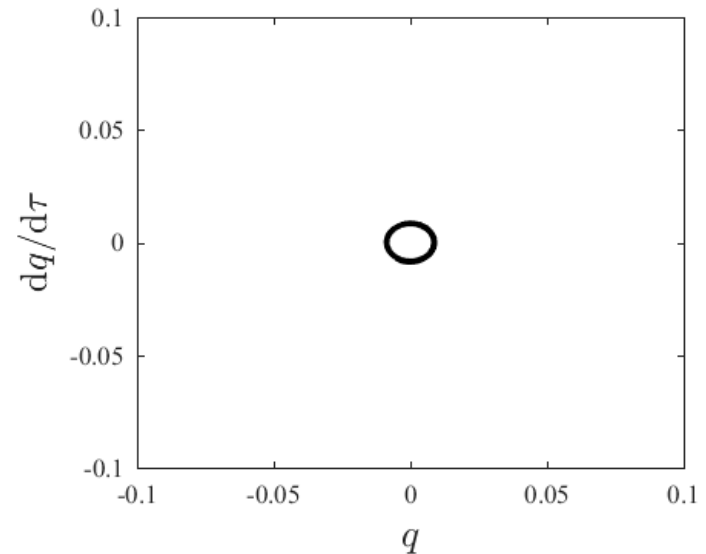

(b)

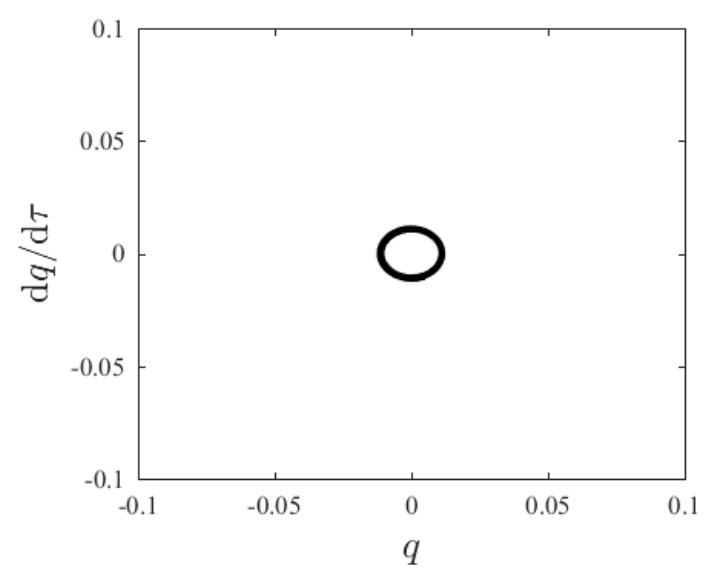

(d)

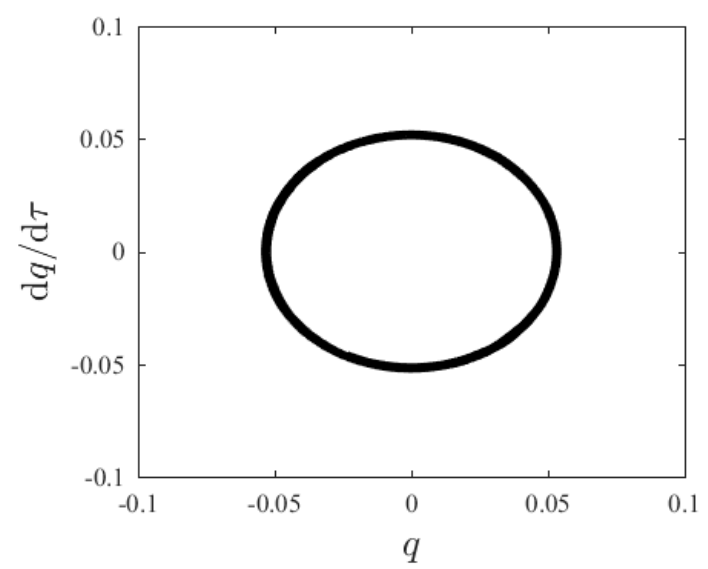

(f)

Figure 4. Cont. 


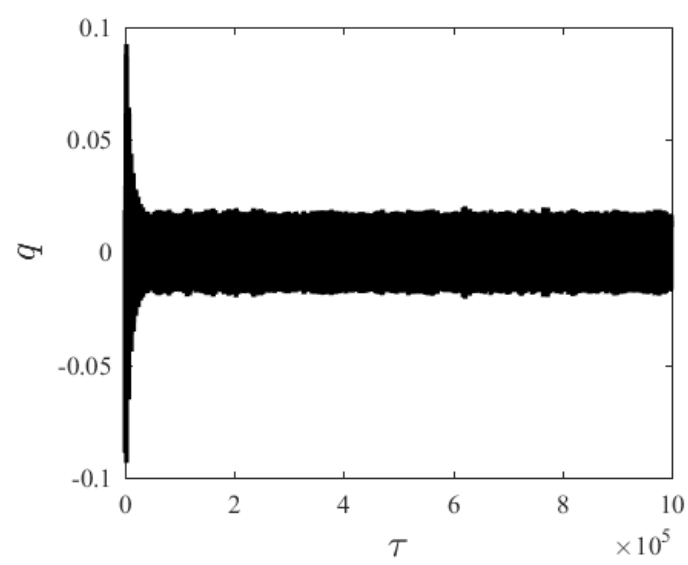

(g)

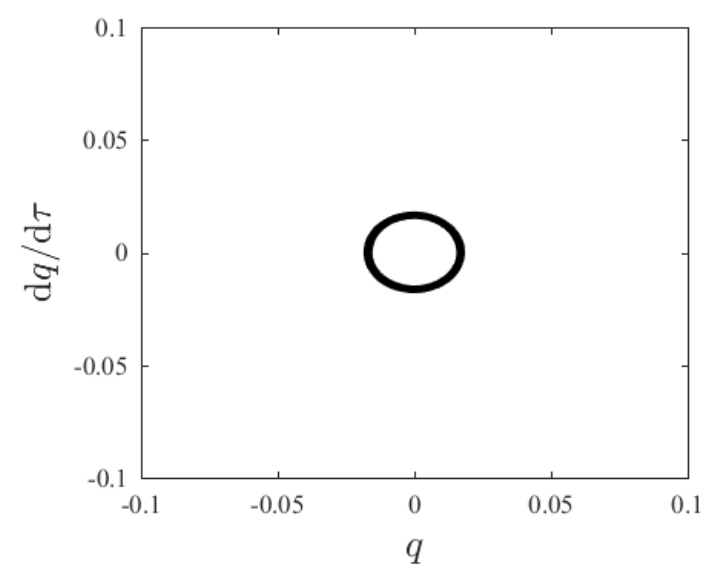

(h)

Figure 4. Time history curves and phase diagrams of $q$ at different axial velocities $v$. (a) displacement-time history curve at $v=10 \mathrm{~m} / \mathrm{s}$, (b) displacement-velocity phase diagram at $v=10 \mathrm{~m} / \mathrm{s}$, (c) displacement-time history curve at $v=50 \mathrm{~m} / \mathrm{s}$, (d) displacement-velocity phase diagram at $v=50 \mathrm{~m} / \mathrm{s}$, (e) displacement-time history curve at $v=90 \mathrm{~m} / \mathrm{s}$, (f) displacement-velocity phase diagram at $v=90 \mathrm{~m} / \mathrm{s}$, (g) displacement-time history curve at $v=120 \mathrm{~m} / \mathrm{s}$, (h) displacement-velocity phase diagram at $v=120 \mathrm{~m} / \mathrm{s}$.

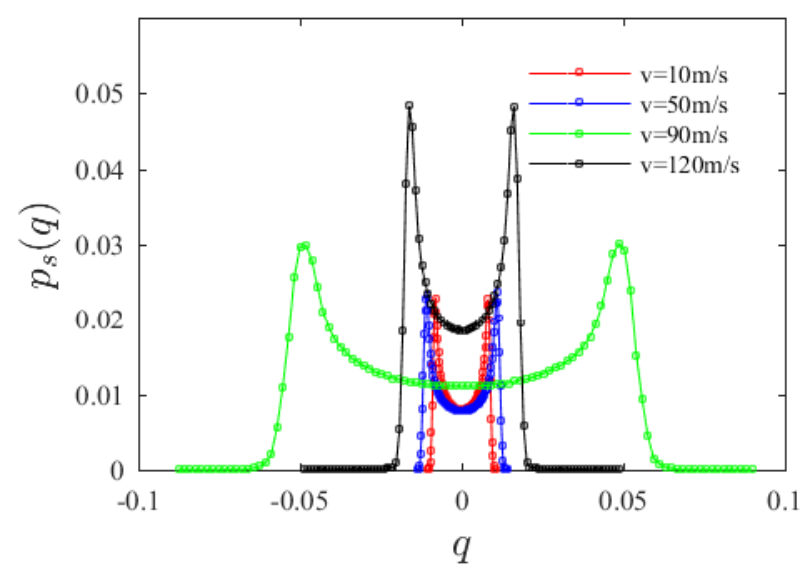

Figure 5. Variation of system marginal probability density function with axial velocity $v_{0}$.

As axial velocity increases, the shape of the marginal probability density curve does not change qualitatively. Comparison of the power spectral density curves of the transverse displacement of the laminated SMA beam under four different velocities reveals that, under a small velocity, the power spectral density curve contains several energy-concentrated frequency components. The energy at the natural frequency is prominent, whereas those at the subsequent frequency components are less impressive; as axial velocity increases, the second frequency component gradually disappears, as shown in Figure 6. With the increase in axial velocity, the system internal energy shows the following transformation: the width of the spectrum first narrows sharply then gradually broadens, with the maximum standing at the system natural frequency all the time. The power spectral density value at the system natural frequency first increases and then begins to decrease when the velocity is greater than $v=90 \mathrm{~m} / \mathrm{s}$. 


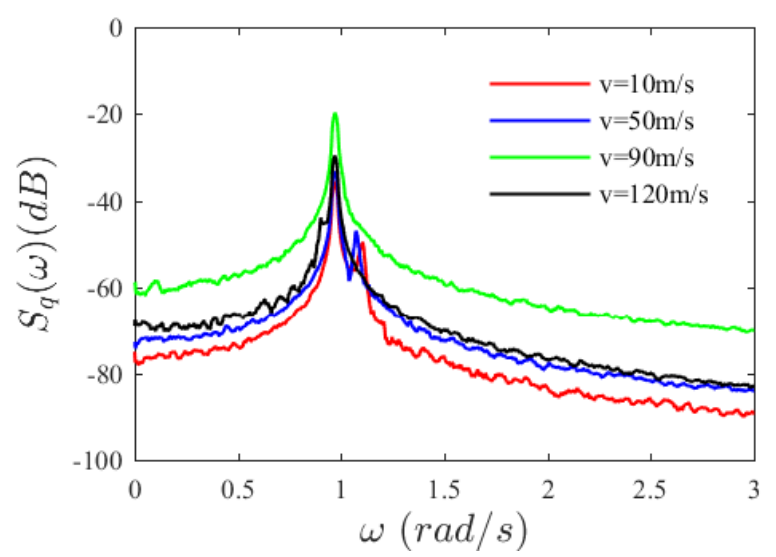

(a)

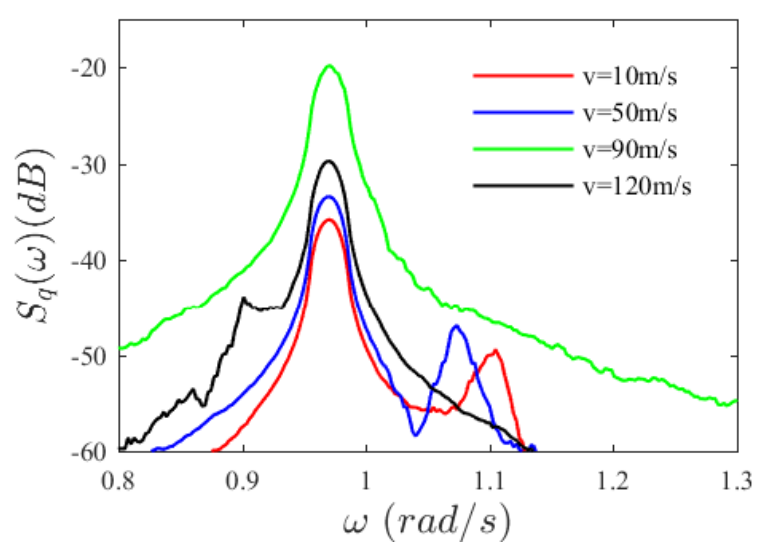

(b)

Figure 6. Variation of power spectral density with axial velocity. (a) $\omega$ from 0 to $3 \mathrm{rad} / \mathrm{s}$ (b) $\omega$ from 0.8 to $1.3 \mathrm{rad} / \mathrm{s}$.

\section{Discussion}

In this paper, nonlinear random parameter vibration of variable-speed axially moving SMA-laminated beam is studied. Compared with the standard limit cycle oscillation of deterministic systems, the time history curve of SMA-laminated beams shows a large oscillation attributed to the random axially moving velocity disturbance. With the increase in the intensity of random axial velocity disturbance, the randomness of the response time history curve of the system increases. As a result, the time history curve becomes more disordered.

Laminated structures are seldom considered in the modeling of axially moving beams or plates in the existing literature, most of which studied nonlinear dynamics such as internal resonance, principal resonance, and bifurcation chaos of axially moving beams and plates. The laminated structure studied in this paper is a common structural form consisting of SMA as the surface and linear elastic material as the sandwich. More importantly, the effect of random axial velocity disturbance on nonlinear random parameter vibration of laminated structures in this paper is rarely mentioned in the existing literature.

Ref. [38] considered the nonlinear random vibration of axially moving SMA-laminated beams under the simultaneous presence of transverse harmonic excitation and random disturbance. Its random excitation is forced excitation in essence. In this paper, the influence of velocity random disturbance is studied, which is parametric random excitation in essence. So, there are essential differences between this paper and Ref. [38]. However, no matter what kind of random factor exists, the time history curve or phase diagram of the system response will be greatly oscillated, and the greater the intensity of the random factor, the stronger the randomness of the system response will be. The conclusion obtained in Figure 7 in Ref. [38] is similar to that in this paper, and this conclusion can be verified mutually.

The SMA Falk's polynomial model is used to analyze the effects of axial movement and random perturbation in this paper. The advantage of this polynomial model is that it can be used to describe the basic constitutive relations of SMA and it is widely used, while the limitation is that it is simple. In the following work, the nonlinear stochastic dynamics of SMA-laminated plates under the coupling action of multiple fields (including temperature fields) based on complex SMA constitutive relations model will be considered.

\section{Conclusions}

The parametric random vibration of axially moving laminated SMA beams subject to random perturbation was investigated. The dynamic equation of laminated SMA beams subject to uniform transverse loading was established. The random vibration equation was numerically simulated via the Monte Carlo method. The system steady-state response was analyzed in the time and frequency domains: 
As random perturbation intensity increases, large-amplitude oscillation appears randomly in the steady-state response. However, the marginal density curve of the system steady-state response does not change qualitatively. Changed random perturbation intensity does not induce a phase transfer in the system.

As the axial velocity increases, the system steady-state response gradually increases from small-amplitude oscillation and then gradually decreases. As the axial velocity gradually decreases, the width of the spectrum first narrows sharply then gradually broadens. A second energy-concentrated frequency component appears on the power spectral density curve, with the maximum width standing at the system natural frequency all the time.

Author Contributions: Conceptualization, Y.H.; data curation, Y.H.; funding acquisition, M.G.; investigation, J.G.; methodology, Y.H.; project administration, Y.H. and M.G.; resources, M.G.; supervision, M.G.; validation, Y.H. and M.G.; visualization, J.G.; writing-original draft, Y.H., M.G. and J.G.; writing-review and editing, M.G. and Y.H. All authors have read and agreed to the published version of the manuscript.

Funding: This research was funded by the National Natural Science Foundation of China, grant numbers 11902287 and 32072786; the Technical Innovation Guide Plan of Shandong Province: Shandong-Chongqing Total Cooperation Project grant number 2020LYXZ021; the Open Project Program of Tianjin Key Laboratory of Microgravity and Hypogravity Environment Simulation Technology, grant number TJWDZL2019KT004; and the Natural Science Foundation of Tianjin, grant number 19JCYBJC19100.

Data Availability Statement: The data presented in this study are available on request from the corresponding author.

Conflicts of Interest: The authors declare no conflict of interest.

\section{References}

1. Chen, S.H.; Huang, J.L. On internal resonance of nonlinear vibration of axially moving beams. Acta Mech. Sin. 2005, 37, 57-63.

2. Ding, H.; Chen, L.Q.; Zhang, G.C. Advances in Nonlinear Models for Transverse Vibration of Axially Moving Beams. J. Dyn. Control 2013, 11, 20-30.

3. Yang, X.D. Dynamical Analysis of Transverse Vibrations of Axially Moving Viscoelastic Beams. Ph.D. Thesis, Shang Hai University, Shanghai, China, 2004.

4. Liu, X.G.; Tang, Y.Q.; Zhou, Y. Comparison of Vibration Characteristics of Three Typical Axially Moving Structures. Chin. J. Theor. Appl. Mech. 2020, 52, 522-532.

5. Ding, H.; Chen, L.Q. Transverse Non Linear Forced Vibration of Axially Moving Iscoelastic Beam. J. Vib. Shock 2009, $28,128-131$.

6. Al-Bedoor, B.O.; Khulief, Y.A. An Approximate Analytical Solution of Beam Vibrations During Axlal Motion. J. Sound Vib. 1996, 192, 159-171. [CrossRef]

7. Sze, K.Y.; Chen, S.H.; Huang, J.L. The Incremental Harmonic Balance Method for Nonlinear Vibration of Axially Moving Beams. J. Sound Vib. 2005, 281, 611-626. [CrossRef]

8. Özhan, B.B. Vibration and Stability Analysis of Axially Moving Beams with Variable Speed and Axial Force. Int. J. Struct. Stab. Dyn. 2014, 14, 1450015. [CrossRef]

9. Lenci, S.; Rega, G. Axial-transversal Coupling in The Free Nonlinear Vibrations of Timoshenko Beams with Arbitrary Slenderness and Axial Boundary Conditions. Proc. Math. Phys. Eng. Sci. 2016, 472, 20160057. [CrossRef]

10. Xiao, G.; Chen, B.; Li, S.; Zhuo, X. Fatigue life analysis of aero-engine blades for abrasive belt grinding considering residual stress. Eng. Faire Anal. 2022, 131, 105846. [CrossRef]

11. Liu, C.; Zhao, Y.; Wang, Y.; Zhang, T.; Jia, H. Hybrid Dynamic Modeling and Analysis of High-Speed Thin-Rimmed Gears. J. Mech. Des. 2021, 143, 123401. [CrossRef]

12. Jin, X.; Chen, Y.; Wang, L.; Han, H.; Chen, P. Failure prediction, monitoring and diagnosis methods for slewing bearingsof large-scale wind turbine: A review. Measurement 2021, 172, 10855. [CrossRef]

13. Mirzaeifar, R.; DesRoches, R.A.; Yavari, A. Combined Analytical, Numerical, and Experimental Study of Shape-memory-alloy Helical Springs. Int. J. Solids Struct. 2011, 48, 611-624. [CrossRef]

14. Shao, B.; Ren, Y.S. Analysis of Free Vibrations of Shape Memory Alloy Hybrid Composite Beams. Eng. Mech. $2003,20,183-187$.

15. Shao, B.; Ren, Y.S. The Semi-Active Control of Shape Memory Alloy Composite Beam. Mech. Eng. 2004, 26, 16-19.

16. Ren, Y.S.; Liu, T.R.; Yang, S.L.; Wang, X.H. Active Deformation Models of Sma Fiber Hybrid Thin-Wall-ed Laminated Beams. Chin. J. Solid Mech. 2010, 31, 228-236.

17. Collet, M.; Foltête, E.; Lexcellent, C. Analysis of The Behavior of a Shape Memory Alloy Beam under Dynamical Loading. Eur. J. Mech. A/Solids 2001, 20, 615-630. [CrossRef] 
18. de Matos Junior, O.D.; Donadon, M.V.; Castro, S.G.P. Aeroelastic Behavior of Stiffened Composite Laminated Panel with Embedded SMA Wire Using the Hierarchical Rayleigh-Ritz Method. Compos. Struct. 2017, 181, 26-45. [CrossRef]

19. Zhang, L.Y.; Zhou, S.; Meng, W.Q.; Piao, X.D. Expermental Study on Random Vibration of Avaiation Conduit with Memory Alloy Joint. Chin. J. Constr. Mach. 2018, 16, 95-100.

20. Razavilar, R.; Fathi, A.; Dardel, M.; Hadi, J.A. Dynamic analysis of a shape memory alloy beam with pseudoelastic behavior J. Intell. Mater. Syst. Struct. 2018, 29, 1835-1849. [CrossRef]

21. Nassiri-monfared, A.; Baghani, M.; Zakerzadeh, M.R.; Fahimi, P. Developing a Semi-analytical Model for Thermomechanical Response of SMA Laminated Beams, Considering SMA Asymmetric Behavior. Meccanica 2018, 53, 957-971. [CrossRef]

22. Zhang, X.; Gao, M.; Hao, Y. The 1/3rd Subharmonic and 3rd Superharmonic Resonance of a Shape Memory Alloy (SMA) Laminated Beam. J. Theor. Appl. Mech. 2020, 59, 27-41. [CrossRef]

23. Nejati, M.; Ghasemi-Ghalebahman, A.; Soltanimaleki, A.; Dimitri, R.; Tornabene, F. Thermal Vibration Analysis of SMA Hybrid Composite Double Curved Sandwich Panels. Compos. Struct. 2019, 224, 111035. [CrossRef]

24. Samadpour, M.; Asadi, H.; Wang, Q. Nonlinear Aero-thermal Flutter Postponement of Supersonic Laminated Composite Beams with Shape Memory Alloys. Eur. J. Mech.-A/Solids 2016, 57, 18-28. [CrossRef]

25. Li, B.; Tang, Y.Q.; Ding, H.; Chen, L.Q. Nonlinear Vibrations of Axially Moving Viscoelastic Timoshenko Beams under Strong External Excitation. J. Vib. Shock 2012, 31, 142-146.

26. Ding, H.; Yan, Q.Y.; Chen, L.Q. Chaotic Dynamics in The Forced Nonlinear Vibration of an Axially Accelerating Viscoelastic Beam. Acta Phys. Sin 2013, 62, 1-7. [CrossRef]

27. Ding, H.; Tan, X.; Zhang, G.C.; Chen, L.Q. Equilibrium Bifurcation of High-speed Axially Moving Timoshenko Beams. Acta Mech 2016, 227, 3001-3014. [CrossRef]

28. Wang, J.; Hu, Y.D. Magneto-elastic Primary Resonance of Axially Moving Current-carrying Beams in Magnetic Fieid. J. Vib. Shock 2016, 35, 65-73.

29. Wang, J.; Hu, Y.D.; Su, Y.; Gong, L.F.; Zhang, Q.N. Magneto-elastic internal resonance of an axially moving conductive beam in the magnetic field. J. Theor. Appl. Mech. 2019, 57, 179-191. [CrossRef]

30. Tang, Y.; Ma, Z. Nonlinear Vibration of Axially Moving Beams with Internal Resonance, Speed-dependent Tension, and Tensiondependent Speed. Nonlinear Dyn. 2019, 98, 2475-2490. [CrossRef]

31. Shao, M.; Wu, J.M.; Wang, Y.; Wu, Q.M. Nonlinear Parametric Vibration and Chaotic Behaviors of an Axially Accelerating Moving Membrane. Shock Vib. 2019, 2019, 6294814. [CrossRef]

32. Sahoo, B.; Panda, L.N.; Pohit, G. Two-frequency Parametric Excitation and Internal Resonance of a Moving Viscoelastic Beam. Nonlinear Dyn. 2015, 82, 1721-1742. [CrossRef]

33. Yan, T.; Yang, T.Z.; Ding, H.; Chen, L.Q. Direct Multiscale Analysis of The Stability of an Axially Moving Compressible Sandwich Beam with Time-dependent Velocity. J. Vib. Shock. 2019, 38, 40-44.

34. Hu, R.C.; Zhang, D.X.; Huan, R.H.; Deng, Z.C. Response and reliability analysis of random time-delay controlled systems undergo wide-band random excitations. Probabilistic Eng. Mech. 2021, 67, 103191. [CrossRef]

35. Hu, R.C.; Gu, X.D.; Deng, Z.C. Stochastic response analysis of multi-degree-of-freedom vibro-impact system undergoing Markovian jump. Nonlinear Dyn. 2020, 101, 823-834. [CrossRef]

36. Hu, R.C.; Lü, Q.F. Optimal Time-Delay Control for Multi-Degree-of-Freedom Nonlinear Systems Excited by Harmonic and Wide-Band Noises. Int. J. Struct. Stab. Dyn. 2021, 21, 2150053. [CrossRef]

37. Paiva, A.; Savi, M.A. An Overview of Constitutive Models for Shape Memory Alloys. Math. Probl. Eng. 2005, 2006, 056876. [CrossRef]

38. Hao, Y.; Gao, M.L. Traverse Vibration of Axially Moving Laminated SMA Beam considering Random Perturbation. Shock. Vib. 2019, 2019, 6341289.

39. Hao, Y.; Gao, M.; Hu, Y.; Li, Y. Nonlinear Dynamic Analysis of Axially Moving Laminated Shape Memory Alloy Beam with 1:3 Internal Resonance. Materials 2021, 14, 4022. [CrossRef] 